Revista Española de Derecho Internacional Sección INFORMACIÓN Y DOCUMENTACIÓN DIPr

Vol. 67/1, enero-junio 2015, Madrid, pp. 329-356 http://dx.doi.org/10.17103/redi.67.1.2015.4b (C) 2015 Asociación de Profesores de Derecho Internacional

y Relaciones Internacionales ISSN: 0034-9380; E-ISSN: 2387-1253

\title{
B) DERECHO INTERNACIONAL PRIVADO
}

\author{
Selección y coordinación a cargo de \\ Joaquim-J. Forner Delaygua \\ Catedrático de Derecho internacional privado \\ Universidad de Barcelona
}

SUMARIO: 1. EL REGLAMENTO 655/2014 DEL PARLAMENTO EUROPEO Y DEL CONSEJO, DE 15 DE MAYO, POR EL QUE SE ESTABLECE EL PROCEDIMIENTO RELATIVO A LA ORDEN EUROPEA DE RETENCIÓN DE CUENTAS A FIN DE SIMPLIFICAR EL COBRO TRANSFRONTERIZO DE DEUDAS EN MATERIA CIVIL Y MERCANTIL.-2. RESPONSABILIDAD FINANCIERA RESULTANTE DE LOS ARBITRAJES DE INVERSIÓN CONSTITUIDOS SOBRE LA BASE DE LOS FUTUROS ACUERDOS DE INVERSIÓN DE LA UNIÓN EUROPEA.-3. LAS RELACIONES DE LA UNIÓN EUROPEA CON LOS PAÍSES DE PEQUEÑA DIMENSIÓN TERRITORIAL. ESPECIAL REFERENCIA AL PRINCIPADO DE ANDORRA.-4. LA NUEVA LEY 14/2014 DE NAVEGACIÓN MARÍTIMA DESDE LA ÓPTICA DEL DERECHO INTERNACIONAL PRIVADO.-5. 24. ${ }^{a}$ REUNIÓN DEL GRUPO EUROPEO DE DERECHO INTERNACIONAL PRIVADO (FLORENCIA, 19 A 21 DE SEPTIEMBRE DE 2014).-6. CELEBRACIÓN DEL 50. ${ }^{\circ}$ ANIVERSARIO DE LA RIVISTA DI DIRITTO INTERNAZIONALE PRIVATO E PROCESSUALE (MILÁN, 23 DE OCTUBRE DE 2014).-7. DECISIÓN DE LA HIGH COURT DE LONDRES, FAMILY DIVISION, RELATIVA A LA ATRIBUCIÓN FRAUDULENTA DE COMPETENCIA A LOS TRIBUNALES INGLESES EN 180 CASOS DE DIVORCIO.

1. EL REGLAMENTO 655/2014 DEL PARLAMENTO EUROPEO Y DEL CONSEJO, DE 15 DE MAYO, POR EL QUE SE ESTABLECE EL PROCEDIMIENTO RELATIVO A LA ORDEN EUROPEA DE RETENCIÓN DE CUENTAS A FIN DE SIMPLIFICAR EL COBRO TRANSFRONTERIZO DE DEUDAS EN MATERIA CIVIL Y MERCANTIL

1. El Reglamento (UE) núm. 655/2014 del Parlamento Europeo y del Consejo, de 15 de mayo, por el que se establece el procedimiento relativo a la orden de retención de cuentas a fin de simplificar el cobro transfronterizo de deudas en materia civil y mercantil, en síntesis, regula el procedimiento para que un acreedor pueda solicitar 
judicialmente que una entidad bancaria bloquee las cuentas del deudor en un asunto transfronterizo. El fin es garantizar y simplificar el cobro de una deuda pecuniaria a escala de la Unión Europea siempre que existan indicios probados de riesgo de que se retiren los fondos por parte del deudor de modo que no podría ejecutarse el crédito (periculum in mora). Dicha medida cautelar, alternativa al uso de las previstas en la normativa nacional (art. 1.2), puede accionarse antes, durante o después de reconocerse el crédito como título ejecutivo por resolución judicial, transacción judicial o documento público con fuerza ejecutiva. Y además, regula la posibilidad que el acreedor añada a la solicitud de la orden europea de retención de cuenta una petición de obtención de información sobre las cuentas que el deudor pueda tener en otros Estados miembros (art. 14).

El Reglamento contiene normas de DIPr sobre competencia judicial internacional (p. ej., para determinar el tribunal o autoridad competente para dictar la orden europea de retención de cuenta), y ley aplicable (p. ej., sobre la ley aplicable a la responsabilidad del acreedor). Asimismo, el Reglamento prevé, una vez obtenida la orden de retención de cuenta, el procedimiento de ejecución transfronterizo intraeuropeo de esta orden eliminando el exequátur.

2. El fundamento del Reglamento parte de la insuficiencia del Reglamento 44/2001 (RBI) para hacer efectivas las medidas cautelares para garantizar la ejecución de los créditos pecuniarios en la Unión Europea. Por un lado, en el caso que se solicitasen medidas provisionales o cautelares al tribunal del Estado miembro donde debían desplegar efectos (lugar donde se encuentra la cuenta bancaria del deudor), éstas se encontraban limitadas a las previstas en el ordenamiento del Estado miembro solicitado (art. 31 RBI y art. 35 RBI bis) y se seguiría un proceso paralelo al principal. El resultado es poco efectivo cuando lo que se requiere es celeridad. Esta posibilidad subsiste y es alternativa al uso del Reglamento 644/2014. Por otro lado, cuando las medidas provisionales eran adoptadas por el tribunal que conociere del fondo del asunto requerían de un exequátur comportando dualidad de procedimientos y dilación en el proceso (Fernández Rozas, J. C. y Sánchez Lorenzo, S., Derecho internacional privado, Pamplona, Thomson Reuters, 2013, p. 89). El Reglamento 644/2014, en cambio, prevé que la medida cautelar sea dictada por el tribunal que conoce del fondo del asunto y que esta orden europea de retención sea reconocida en los otros Estados miembros y aplicada de inmediato por la autoridad del Estado miembro de ejecución. Por ello, el Reglamento no se remite al nuevo RBI bis que, a pesar de prever el reconocimiento y ejecución automático de las medidas cautelares, continúa siendo inaplicable a las adoptadas inaudita parte debitoris, que es el procedimiento previsto en el Reglamento 655/2014 tal y como se presentará en líneas posteriores. Otro fundamento de la aprobación del Reglamento 655/2014 es que completa los instrumentos europeos en materia de tutela de los créditos transfronterizos como son el título ejecutivo europeo, el proceso monitorio europeo y el proceso europeo de escasa cuantía (Domínguez Ruiz, L., Reclamación de deudas transfronterizas, Pamplona, Thomson Reuters, 2013, pp. 257-259).

En este contexto y con el objetivo de dar mayor eficacia a la ejecución de las resoluciones judiciales en la Unión Europea, la Comisión presentó dos libros verdes [documentos $\operatorname{COM}(2006) 618$ final y COM(2008) 128 final]. El primero, proponía el sistema de embargo preventivo de cuentas eliminando los obstáculos a la libre circulación de requerimientos de pago entre distintos Estados miembros y, por tanto, facilitando la ejecución de créditos pecuniarios. El segundo, abordaba la difícil cuestión, también en ámbito interno, de la investigación judicial sobre el paradero del patrimonio del 
deudor, así como buscaba mejorar el derecho de los acreedores, y todo ello garantizando la protección de datos personales del deudor y asegurando la proporcionalidad de las medidas. Después de los preceptivos informes y recomendaciones de las distintas instituciones europeas, y el proyecto de Reglamento [documento COM(2011) 455 final], el resultado ha sido el Reglamento 655/2014 objeto de esta nota informativa.

3. El Reglamento ya en vigor, fue publicado en junio de 2014 ( $D O$ L 189, de 27 de junio de 2014) y será aplicable a partir del 18 de enero de 2017. Por tanto, dos años y medio para que los Estados miembros adapten sus legislaciones a esta norma europea, así como para que notifiquen a la Comisión pluralidad de información sobre su Derecho procesal interno. Ello es esencial, dado que son múltiples las remisiones que el Reglamento realiza a la legislación interna de los Estados (véase el listado que recoge todas las remisiones en el art. 50). El legislador español tendrá que comprobar que su legislación procesal interna (y, en su caso, el Anteproyecto de ley de cooperación jurídica internacional en materia civil, de 4 de julio de 2014) sea compatible con el nuevo Reglamento 655/2014 y deberá facilitar la información requerida medio año antes de su aplicación para poder ser publicada en la Red Judicial Europea en materia civil y mercantil.

4. Su ámbito de aplicación material son las deudas pecuniarias civiles y mercantiles en asuntos transfronterizos (art. 2). Se excluyen las materias: fiscal, aduanera, administrativa, y la responsabilidad del Estado por actos u omisiones en el ejercicio de su autoridad. También son excluidos los derechos de propiedad derivados del régimen matrimonial o análogo y los alimentos derivados de sucesiones y testamentos (materias que sí estaban incluidas en la propuesta de Reglamento); los créditos de deudores sobre los cuales se hayan iniciado procedimientos de insolvencia; la seguridad social; el arbitraje y las cuentas bancarias que gocen de inmunidad frente al embargo según el Derecho del Estado miembro en el que se tenga la cuenta. Sí que se aplicará a las obligaciones de alimentos que no sean por causa de muerte; a una pequeña deuda comercial (cdo. 18) y a créditos que aún no sean exigibles, cuando sea posible determinar la cuantía, incluidas las derivadas de acciones en materia delictual o cuasidelictual así como «de acciones civiles por daños y perjuicios o de restitución basadas en un acto que dé lugar a un proceso penal» (cdo. 12). El legislador europeo ha optado por dejar la decisión de si se aplica el Reglamento a los instrumentos financieros (como acciones o bonos) para el año 2022 que será cuando evaluará y revisará la aplicación del Reglamento (art. 53).

El Reglamento 655/2014 sólo será de aplicación en los asuntos transfronterizos (art. 2.1) que define (art. 3): cuando la cuenta bancaria y el acreedor tengan domicilios en Estados miembros distintos; y, cuando la cuenta bancaria y el órgano jurisdiccional al que se solicite la orden de retención (atendiendo al reparto competencial que prevé el art. 6) estén en Estados miembros distintos.

5. Como Reglamento, será obligatorio en todos sus elementos y directamente aplicable en los Estados miembros con arreglo a los Tratados. De momento, será aplicable a 26 de los Estados de la Unión Europea, ya que Irlanda ha notificado su deseo de participar en la adopción y aplicación de éste, mientras que el Reino Unido y Dinamarca no participan, de forma que no quedan sujetos a su aplicación. Tal como indica el considerando 48, el procedimiento regulado debe estar «únicamente a disposición de acreedores domiciliados en un Estado miembro vinculado por el presente Reglamento, y las órdenes dictadas de conformidad con el presente Reglamento únicamente han de afectar a la preservación de cuentas bancarias mantenidas en ese Estado miembro". 
6. El procedimiento previsto en el Reglamento 655/2014 parte de la existencia de un acreedor, que puede ser persona física o jurídica o, una entidad domiciliada en un Estado miembro que tenga capacidad para ser parte con arreglo al Derecho de un Estado miembro; que tiene un crédito determinable en dinero y exigible por título ejecutivo (sea una resolución judicial, una transacción judicial o un documento público con fuerza ejecutiva) o; una pretensión de pago respecto a un deudor contra el cual el acreedor solicite, como medida cautelar ante autoridad judicial, una orden de retención de cuenta para que la autoridad competente retenga de la cuenta del banco el fondo que asegure el crédito (definiciones en el art. 4). Al respecto, varias cuestiones son destacables:

El acreedor puede solicitar la orden europea de retención de cuenta (en adelante, orden de retención) antes de que se incoe un procedimiento en un Estado miembro contra el deudor ante el tribunal que tendrá que resolver el fondo del asunto, o en cualquier momento del procedimiento. En este caso, la autoridad jurisdiccional competente para emitir la orden de retención será la misma que conozca el fondo del asunto de conformidad con las correspondientes normas de competencia aplicables (art. 5.1). Estará obligado a incoar el procedimiento, en general, en el plazo de treinta días desde la solicitud de la orden de retención. En caso contrario la medida cautelar será revocada o se dejará sin efecto (art. 10) e incurrirá en responsabilidad del acreedor [art. 13.2.a)].

Asimismo, podrá solicitar la orden de retención después de haber obtenido en un Estado miembro el título ejecutivo que obligue al deudor a pagar una deuda a su favor. En este supuesto serán competentes los órganos jurisdiccionales del Estado miembro en el que se haya dictado la resolución o aprobado la transacción judicial; en relación con el documento público ejecutivo, el Reglamento remite al órgano jurisdiccional designado a tal fin en el Estado miembro en el que dicho documento se haya formalizado (art. 6.3 y 4).

La norma de competencia judicial incluye una excepción a la norma general cuando el deudor sea un consumidor, ya que prevé como competentes los órganos jurisdiccionales del Estado miembro en el que esté domiciliado el deudor. Una vez más, el legislador europeo regula normas de especial protección a la parte débil del contrato, cuando este contrato sea ajeno a la actividad o profesión del deudor (art. 6.2).

Para la solicitud de la orden de retención se utilizará un formulario, que pondrá a disposición la Comisión, en el que se incluirá toda la información necesaria y se vehiculará según las normas procesales del Estado miembro en el que se presente la solicitud (art. 8). Es necesario que la solicitud, y por tanto el acreedor, convenza al órgano jurisdiccional mediante la presentación de pruebas de que existe la necesidad urgente de una medida cautelar por existir un «riesgo real de que, sin dicha medida, la ejecución ulterior del crédito frente al deudor se verá impedida o resultará considerablemente más difícil» (periculum in mora). Para los casos en que aún no exista un título ejecutivo, el acreedor deberá probar que su pretensión frente al deudor tiene probabilidades de prosperar en cuanto al fondo (art. 7) (fumus boni iuris). Los medios de prueba, valoración y proceso probatorio se regirán por el Derecho nacional del órgano jurisdiccional que conoce de la solicitud y que adoptará su resolución mediante procedimiento escrito (art. 9) en el plazo previsto en el Reglamento (antes de tener el título ejecutivo dispone de diez días hábiles y si es, ex post, cinco días hábiles, art. 18) y dictada utilizando formulario (art. 19). La orden de retención se dictará por la cuantía acreditada, determinada por la ley aplicable a la deuda subyacente e incluirá, en su caso, los intereses y/o costes (art. 17.4) siempre que éstos no constituyan una 
violación de las leyes de policía del Estado miembro que dicta la orden de retención (art. 15). El acreedor podrá recurrir la resolución por la que se deniega la orden de retención (art. 21).

El procedimiento de solicitud y aprobación de la orden de retención está previsto que sea inaudita parte debitoris con el fin de garantizar el efecto sorpresa para evitar cualquier iniciativa fraudulenta del deudor que provoque la ineficacia de ésta cuando la finalidad propia es el cobro del crédito (cdo. 15). No obstante, ello no desprotege al deudor, en cuanto que el procedimiento previsto se fundamenta en la prueba aportada por el acreedor de la necesidad de realizar la pretendida retención antes de tener el título ejecutivo (fumus boni iuris), así como la obligación, como norma general, de que el acreedor deba prestar caución cuando se solicita la retención antes de tener reconocido el crédito (art. 12); asimismo prevé el sistema de responsabilidad del acreedor por los daños y perjuicios derivados de la orden de retención a la que se aplicará la ley del Estado miembro de ejecución, aunque prevé una norma de conflicto subsidiaria para el caso de que se retengan cuentas en más de un Estado miembro (art. 13) y; la posibilidad del deudor de impugnar la orden europea de retención (art. 33).

A pesar de estas medidas, la ausencia de garantías de defensa del deudor, en cuanto que no se le notifica la solicitud de la orden de retención ni se le oirá antes de dictar la orden (art. 11) puede crear fricciones entre las diversas tradiciones procesales de los Estados miembros. Si bien es cierto que cabe presentar recurso por parte del deudor por falta de notificación en un plazo determinado (el Reglamento regula un régimen de notificación concreto sin remitirse al Reglamento 1393/2007, art. 28), este recurso es a posteriori de la cumplimentación de la orden de retención (arts. 25, 28, 33). Como señala Eva de Götzen, no todos los ordenamientos nacionales prevén la emisión e inmediata ejecución de medidas cautelares sin previa audiencia del demandado, garantizando el principio de contradicción, como sucede en el ordenamiento italiano (GöTZEN, E. DE, SIDI-Blog, de 13 de noviembre de 2014). En Derecho español, el título VI de la LEC incluye la posibilidad de solicitar medidas cautelares a los tribunales españoles por quien acredite ser parte de un proceso judicial en un país extranjero y, en su caso, aplicar lo que prevén los tratados (léanse reglamentos europeos) (arts. 722 y 724 LEC). La regulación sobre medidas cautelares prevista en nuestra norma procesal es similar a la del Reglamento 644/2014 [justificación por parte del acreedor de la necesidad de la medida cautelar por peligro de la mora procesal; la prestación de caución suficiente (como norma general) para responder de posibles daños y perjuicios que la adopción de la medida cautelar pudiera causar al patrimonio del demandado; posibilidad de caución sustitutoria, etc.]. Ahora bien, como regla general, "el tribunal proveerá a la petición de medidas cautelares previa audiencia del demandado», aunque prevé una excepción cuando se acredite que concurren razones de urgencia o cuando la audiencia previa pueda comprometer el buen fin de la medida cautelar (art. 733 LEC, STC 14/1992, de 10 de febrero) y regula las causas de oposición (arts. 739-742 LEC). En la práctica, la jurisprudencia española es muy reacia a adoptar medidas cautelares inaudita parte [PÉREZ DAUDí, V., «Medidas cautelares», en CORBAL FERNÁNDEZ, J. E. et al. (dirs.), Práctica procesal civil, t. IX, pp. 8245 y ss.]. Será necesario esperar a la aplicación práctica del Reglamento 655/2014 por parte de nuestros tribunales y la posibilidad que tiene el deudor de accionar recursos para impugnar la orden de retención ante el órgano competente del Estado miembro de origen, destacando, como motivo, la falta de notificación en el plazo previsto [art. 33.1.b)]. Asimismo, la posibilidad de usar el art. 24 de la Constitución española para alegar el orden público con el fin de impugnar la ejecución de la orden de retención por el deudor ante el Estado de ejecución (art. 34.2), entre otros motivos de oposición (art. 34.1). 
7. Tal y como se ha introducido, el Reglamento 655/2014 regula, necesariamente, el reconocimiento y ejecución de estas órdenes de retención ya que son medidas provisionales y cautelares (cdo. 4) inaudita parte (art. 11) de modo que no se consideran resoluciones en el sentido del art. 2 RBI bis (Miguel Asensio, P. DE, Blog, de 30 de junio de 2014; STJUE de 21 de mayo de 1980, asunto 125/79 Denilauler c. Couchet Frères). El Reglamento regula la supresión del exequátur en el capítulo 3, de suerte que la orden de retención «será reconocida en los demás Estados miembros sin necesidad de procedimiento alguno y tendrá fuerza ejecutiva en los demás Estados miembros sin necesidad de una declaración de fuerza ejecutiva» (art. 22). La autoridad competente del Estado miembro de ejecución dará cumplimiento a la orden de retención con arreglo a su legislación nacional, así que tendrá que aplicarse el Derecho procesal del Estado (art. 46) en cuestiones como son: el cumplimiento del banco; el sistema de retención o trasferencia a una cuenta destinada a la retención; posibilidad de liberación de los fondos por el pago de la deuda; la responsabilidad del banco por incumplimiento de las obligaciones; posibilidad o no de retención de cuentas conjuntas; la determinación de las cantidades inembargables; la prelación de la orden de retención; el procedimiento aplicable al recurso para la impugnación de la orden de retención. A pesar de que la ejecución se realizará con arreglo a los procedimientos aplicables a la ejecución de las órdenes nacionales equivalentes en el Estado de ejecución (art. 23.1), el Reglamento introduce una detallada disciplina autónoma sobre la modalidad procesal de la ejecución de la orden de retención en el sentido que ésta tendrá que transmitirse sin dilación al banco donde se halla la cuenta del deudor y rápidamente retendrá el importe especificado en la orden. Para ello, incluye un modelo sustancialmente diferente al RBI bis (Miguel Asensio, P. DE, Blog, de 30 de junio de 2014; GötZen, E. DE, SIDI-Blog, de 13 de noviembre de 2014). El Reglamento 655/2014 prevé el derecho a recurrir en el capítulo 4 (art. 37) y las vías de recurso disponibles para el deudor, presentadas en líneas precedentes, así como otros recursos a disposición del deudor y del acreedor para solicitar la modificación o revocación de la orden, inclusive admite una actuación de oficio (art. 35). Asimismo, los procedimientos para los recursos (art. 36), el derecho a prestar garantía sustitutoria a solicitud del deudor (art. 38) y el derecho de un tercero a impugnar una orden de retención (art. 39), todo ello remitiéndose en gran medida a las normas procesales y al Derecho de las autoridades de los Estados miembros implicados.

8. Este nuevo Reglamento, como señalaba la Comisión Europea (IP/2013/1209), tendría que evitar que cada año se cancelen deudas por valor de hasta 600 millones de euros, porque a las empresas, sobre todo las PYMES, les resulta demasiado difícil iniciar procedimientos judiciales onerosos y complejos en otros países; dificultad extensible a los ciudadanos cuando los bienes adquiridos en línea no se entregan o un progenitor ausente no paga la pensión desde el extranjero. El nuevo Reglamento complementa los procedimientos de declaración de títulos ejecutivos de créditos regulados hasta el momento en el contexto del espacio judicial europeo, de manera que evita que el deudor retire los fondos durante el tiempo que dure el procedimiento para obtener la declaración de la deuda y su ejecución. Sin lugar a dudas, el Reglamento $655 / 2014$ alcanza los objetivos inicialmente previstos ya que supondrá un procedimiento útil, rápido e innovador que permitirá al acreedor el bloqueo del importe debido en la cuenta del deudor y, en su caso, también la posibilidad de investigar sobre sus activos patrimoniales, con el fin de garantizar y facilitar el cobro o la recuperación de la deuda pendiente a escala de la Unión Europea.

\author{
Maria FONT I MAS \\ Universitat Rovira i Virgili \\ http://dx.doi.org/10.17103/redi.67.1.2015.4b.01
}




\section{RESPONSABILIDAD FINANCIERA RESULTANTE DE LOS ARBITRAJES DE INVERSIÓN CONSTITUIDOS SOBRE LA BASE DE LOS FUTUROS ACUERDOS DE INVERSIÓN DE LA UNIÓN EUROPEA ${ }^{1}$}

1. Tras las modificaciones introducidas por el Tratado de Lisboa, la política comercial común de la Unión Europea (UE) incluye la materia de las inversiones extranjeras directas. En consecuencia, ésta se ha transformado en una materia de la competencia exclusiva de la Unión, constituyendo un cambio radical respecto al reparto competencial previo, donde a los Estados miembros se les reconocía la competencia prácticamente exclusiva para celebrar Acuerdos para la promoción y protección de inversiones (APPRI) con terceros Estados.

2. En el nuevo escenario abierto tras la «revolución» de Lisboa los interrogantes se multiplican. En primer lugar, la UE debe adoptar decisiones de naturaleza política y/o ideológica relacionadas con la elección de los socios preferentes, la elaboración de una agenda negociadora y el diseño de las prioridades y objetivos de la futura política común de inversiones internacionales. En este sentido, la Comunicación de la Comisión, de 7 de julio de 2010, titulada Hacia una Política Global Europea en Materia de Inversión Internacional [documento $\operatorname{COM(2010)~} 343$ final], constituye un documento esencial para comprender el camino iniciado por la UE y las preferencias que inspiran sus primeras decisiones.

En segundo lugar, surgen, también, interrogantes complejos de corte jurídico, sobre cuestiones más técnicas quizás, pero no menos importantes para el éxito de la futura política común. Así, resulta imprescindible ordenar el tránsito de una situación donde existen más de 1.400 APPRI concluidos por los Estados miembros a un futuro de Acuerdos europeos de inversión. En este sentido, es de celebrar la respuesta articulada por la Unión mediante la adopción del Reglamento núm. 1219/2012 del Parlamento Europeo y del Consejo, de 12 de diciembre, por el que se establecen disposiciones transitorias sobre los Acuerdos Bilaterales de Inversión entre Estados Miembros y Terceros Países, si bien es cierto que este Reglamento sólo afecta a los APPRI celebrados por los Estados miembros con terceros Estados (APPRI extra-UE) y no, así, a los APPRI intra-UE. La acomodación de la situación heredada a la nueva competencia exclusiva de la Unión debe lidiar, además, con distintos problemas de Derecho internacional general. Por ejemplo, los que derivan de la disposición que está habitualmente presente en los APPRI y que prevé, una vez hayan terminado éstos, una vigencia adicional de diez o quince años; o las cuestiones relativas a la responsabilidad internacional de las organizaciones internacionales, con las dificultades añadidas que presenta la determinación de la responsabilidad de una organización internacional de integración como la UE en relación con los actos de sus Estados miembros, y con la agravante de la inadecuación o insuficiencia de las soluciones que aporta el Proyecto de Artículos sobre la Responsabilidad de las Organizaciones Internacionales de la Comisión de Derecho Internacional (CDI) de 2011 para estas situaciones.

3. Uno de los elementos fundamentales que debe considerar la política europea de inversiones internacionales se refiere a los mecanismos de arreglo de diferencias entre Estados e inversores y, de forma particular, al arbitraje de inversión. La Comisión ha dejado claro que no está por la labor de renunciar a este mecanismo por considerar que se trata de una «característica tan consolidada de los acuerdos de in-

\footnotetext{
1 Desde una perspectiva distinta, véase en esta Revista, en la Sección de información de Derecho internacional público, la nota de F. PAScual VIVES, pp. 293 y ss.
} 
versión que la ausencia de dicho mecanismo disuadiría a los inversores y haría perder atractivo a una economía con respecto a otras» [véase documento $\operatorname{COM}(2010) 343$ final, p. 10]. Sin embargo, la posible participación futura de la UE en los arbitrajes de inversión cuenta con ciertas limitaciones de partida, como la imposibilidad de ser parte en el Convenio de Washington, de 18 de marzo de 1965, y, por tanto, de servirse del arbitraje CIADI.

4. Si los futuros Acuerdos de inversión europeos incorporan la opción del arbitraje, la Unión debe prepararse para ser parte demandada, y eventualmente condenada, en los procedimientos que inicien los inversores extranjeros. Por tanto, no será de extrañar que la UE deba hacer frente al pago de una indemnización (muchas veces cuantiosa) y a los costes del arbitraje (también cuantiosos) por la violación de uno de sus Acuerdos de inversión.

Tal y como señaló el Parlamento Europeo en su Resolución de 6 de abril de 2011, sobre la Futura Política Europea en Materia de Inversiones Extranjeras, se imponía la necesidad de adoptar un reglamento «sobre el reparto de responsabilidades a nivel nacional y de la UE, en particular en términos financieros, en caso de que la UE pierda un proceso en el contexto de un arbitraje internacional» (párr. 35). Atendiendo a esta petición, se ha adoptado el Reglamento (UE) núm. 912/2014, del Parlamento Europeo y del Consejo, de 23 de julio, por el que se establece un Marco para Gestionar la Responsabilidad Financiera relacionada con los Tribunales de Resolución de Litigios entre Inversores y Estados establecidos por Acuerdos Internacionales en los que la Unión Europea sea Parte (véase Fernández Rozas, J. C., "Conjeturas en torno a la nueva política global europea en materia de inversión internacional tras el Reglamento núm. 912/2014», La Ley Europea, 2014, núm. 18, pp. 5-27).

5. El objetivo principal del Reglamento 912/2014 es, por tanto, determinar los criterios que servirán para delimitar la responsabilidad financiera de la UE y los Estados miembros respecto a los procedimientos arbitrales que traigan causa en la aplicación de un Acuerdo que contenga disposiciones sobre inversión y en el que sea parte la UE o la UE y los Estados miembros (acuerdos mixtos). Además, el Reglamento regula, por un lado, la cuestión del ius standi, es decir, si corresponde a la UE o al Estado miembro actuar como demandado ante el tribunal arbitral que resolverá la controversia y, por otro, las particularidades de los procedimientos arbitrales que vayan a desarrollarse, teniendo en cuenta que tanto la UE como los Estados miembros pueden llegar a tener intereses legítimos en los arbitrajes en los que no participen como demandados.

6. No obstante, existe una cuestión previa a la determinación de la responsabilidad financiera que es fundamental: establecer a quién corresponde la responsabilidad internacional por los comportamientos sometidos al juicio de los árbitros. Para atribuir la responsabilidad internacional, la UE hace suyo el criterio del reparto competencial. De esta forma, «la Unión será en principio responsable de defender cualquier pretensión basada en un incumplimiento de normas incluidas en un acuerdo que sea exclusivamente competencia de la Unión, independientemente de si el trato en cuestión es dispensado por la propia Unión o por un Estado miembro» (cdo. 3 del Reglamento). Este criterio de la competencia no viene recogido y, por tanto, se aleja de las soluciones que se proponen en el proyecto de artículos de la CDI de 2011. Sin embargo, no es desconocido para la práctica de la UE, al incluirse, por ejemplo, en el art. 6.1 del Anexo IX de la Convención de las Naciones Unidas sobre el Derecho del Mar o en el art. 106 del Acuerdo Euromediterráneo celebrado entre la Comunidad Europea y sus Estados miembros y Argelia. 
7. La responsabilidad internacional, en línea de principio, acarrea responsabilidad financiera; es decir, se espera que el sujeto responsable se haga cargo de la obligación de pagar. Sin embargo, el Reglamento 912/2014 aprecia que «no sería [...] justo que la indemnización [...] y los costes de arbitraje fueran pagados con cargo al presupuesto de la Unión cuando el trato haya sido dispensado por un Estado miembro, a menos que dicho trato sea requerido por el Derecho de la Unión» (cdo. 5). El Reglamento, por tanto, desvincula la responsabilidad financiera del criterio de competencia, alegando razones de justicia, aunque deja claro que el reparto de la responsabilidad financiera en él establecido no afectará al reparto competencial previsto en los Tratados constitutivos (art. 1).

La responsabilidad financiera recae sobre el sujeto responsable del trato (art. 3). No es la competencia, sino la autoría del trato discutido, el criterio que hace suyo el Reglamento. De este modo, será la Unión quien asuma la responsabilidad financiera que derive del trato dispensado por las instituciones, los órganos, oficinas u organismos de la Unión. Por el contrario, será el Estado miembro afectado el que asuma la responsabilidad financiera que derive del trato dispensado por dicho Estado. Como excepción lógica será la Unión la que asuma la responsabilidad financiera si el trato dispensado por un Estado miembro ha sido requerido por la Unión, lo que se da en los supuestos en los que el Estado miembro «sólo podría haber evitado la supuesta infracción del acuerdo incumpliendo una obligación establecida en virtud del Derecho de la Unión sin disponer de discrecionalidad ni de margen de apreciación sobre el resultado perseguido» [art. 2.l)].

Un Estado miembro podrá en cualquier momento aceptar voluntariamente asumir la responsabilidad financiera total o parcial en un litigio donde la UE actúe como demandada (art. 12). Sin embargo, también cabe la posibilidad de que el Estado miembro no tenga intención de hacer suya dicha responsabilidad. En supuestos de discrepancia, el Estado miembro y la UE deberán esforzarse para alcanzar un acuerdo o, en última instancia, será la Comisión quien decida el importe que debe pagar el Estado miembro (arts. 3.2 y 19), si bien este último podrá recurrir la decisión por la vía del art. 263 del TFUE.

8. Según el Reglamento, es «equitativo y apropiado» que quien asume la responsabilidad financiera sea quien actúe como parte demandada en el litigio donde se juzgará el trato dispensado al inversor (cdo. 9 y arts. 4 y 9 del Reglamento). Por tanto, el responsable del trato será quien se encargará de defenderlo.

Ahora bien, el Reglamento prevé excepciones a esta regla general. En primer lugar, el Estado interesado (responsable del trato) podrá renunciar a actuar como parte demandada [art. 9.1.b)]. En segundo lugar, para proteger adecuadamente sus intereses, la UE puede decidir actuar como demandada, cuando asuma al menos en parte la posible responsabilidad financiera derivada del litigio [art. 9.2.a)], cuando el litigio esté relacionado también con un trato dispensado por la propia Unión [art. 9.2.b)] o, «cuando se haya impugnado un trato similar en una reclamación conexa contra la Unión ante la OMC, cuando se haya creado un grupo especial y la reclamación se refiera a la misma cuestión jurídica concreta, y cuando sea necesario para garantizar la coherencia de una argumentación en un asunto presentado ante la OMC» (art. 9.3). Salvo en el supuesto del art. 9.2.a), en ninguno de estos casos quedará afectada la responsabilidad financiera del Estado responsable del trato. Es por ello que la Unión, en su condición de demandada, deberá velar por los intereses financieros del Estado miembro afectado (art. 9.4).

9. El Reglamento incorpora distintas disposiciones que, sobre la base del principio de cooperación leal del art. 4.3 del TUE, pretenden asegurar un desarrollo armo- 
nioso de los litigios relacionados con un trato dispensado por un Estado miembro, teniendo en cuenta que cuando el que actúa como demandado es el Estado miembro, la UE puede tener intereses legítimos sobre el asunto y que cuando el demandado sea la UE habrá intereses - principalmente financieros - del Estado miembro afectado que deben protegerse. El Reglamento impone obligaciones, entre otras, de notificación, de facilitar documentos relacionados con el procedimiento, de información, de prestar ayuda y colaboración (véanse los arts. 10 y 11) y, en general, el deber de adoptar «todas las medidas necesarias para defender y proteger los intereses de la Unión y del Estado miembro afectado» (art. 6).

Por último, el Reglamento incluye un capítulo sobre los acuerdos transaccionales que resuelven la controversia en el marco de litigios en los que la UE sea parte demandada. La regla general que inspira este capítulo consiste en dejar en manos del sujeto responsable del trato y de quien asume la responsabilidad financiera (UE o Estado miembro) la decisión de alcanzar un acuerdo de este tipo. En caso de que el litigio comprometa las arcas de la Unión y de un Estado miembro, será la Comisión quien decida en última instancia «sobre la base de un análisis fáctico, exhaustivo y equilibrado y un razonamiento jurídico».

10. El Reglamento 912/2014 viene a sumarse a ese conjunto de medidas que tienen el propósito de preparar el terreno a la nueva política europea de inversiones internacionales; política que, no libre de polémica, está dando sus primeros pasos en las negociaciones abiertas con Canadá, Estados Unidos de América, China, Birmania, India, Singapur, Japón, Egipto, Túnez, Marruecos, Jordania, Malasia, Vietnam y Tailandia. Sin embargo, los criterios para el reparto de la responsabilidad (internacional y financiera) y para la identificación de la parte demandada que propone el Reglamento, si bien surtirán efectos ad intra entre los Estados miembros y la Unión, no encuentran respaldo en las reglas del proyecto de artículos de la Comisión de Derecho Internacional de 2011. Las disposiciones del Reglamento, al igual que el art. 216.2 del TFUE, son «reglas de la organización» para el Derecho internacional y, por tanto, en línea de principio, no vincularán a otros sujetos internacionales con los que la UE celebre Acuerdos de inversión. En este sentido, son varios e interesantes los interrogantes que plantea el (des)encaje de este Reglamento en los parámetros - por otra parte, todavía inciertos- del Derecho internacional general, pero su estudio excede de la finalidad y objeto de la presente nota. No obstante, con el fin de maximizar los efectos y la eficacia del Reglamento 912/2014 sería recomendable que los futuros Acuerdos de inversión de la UE incorporaran una referencia expresa al mismo para que éste desplegara sus efectos ad extra como lex specialis (art. 64 del proyecto de artículos de la Comisión de Derecho Internacional de 2011) y, de este modo, fuera exigible ante las demás partes en el Acuerdo. Una segunda opción pasaría porque esos Acuerdos previesen la competencia de la UE para determinar quién actúa como demandado en los procedimientos iniciados a su abrigo, ya que de este modo se abriría la puerta para que la UE adoptara esta decisión aplicando el Reglamento 912/2014. Esta última opción es la que parece va a hacer suya la UE, por ejemplo, en el Acuerdo Económico y Comercial Global negociado con Canadá (véase el art. X.20 del texto consensuado al término de las negociaciones, en http:// ec.europa.eu/trade/).

Íñigo IRURETAGoiena AgIRREZABaLAGa

Universidad del País Vasco (UPV/EHU)

http://dx.doi.org/10.17103/redi.67.1.2015.4b.02 


\section{LAS RELACIONES DE LA UNIÓN EUROPEA CON LOS PAÍSES DE PEQUEÑA DIMENSIÓN TERRITORIAL. ESPECIAL REFERENCIA AL PRINCIPADO DE ANDORRA}

1. La Unión Europea mantiene relaciones importantes y cada vez más intensas con la República de Islandia, el Reino de Noruega, la Confederación Suiza y con los Estados de pequeña dimensión territorial: el Principado de Liechtenstein, el Principado de Andorra, el Principado de Mónaco y la República de San Marino. El Consejo de la UE considera que las relaciones con estos siete Estados son importantes no sólo por la situación geográfica y una historia común, sino también por compartir intereses, valores, fronteras interiores y exteriores, una identidad europea común y economías de mercado sólidas profundamente integradas en el Mercado único ampliado de la UE.

2. Las relaciones con la República de Islandia han estado marcadas por las negociaciones relativas a un posible acuerdo de adhesión a la UE, que fueron suspendidas por el Gobierno islandés en el año 2013 y por las discusiones en Islandia acerca de su futura política europea. No obstante, el proceso de negociación sigue abierto y el Gobierno islandés está dispuesto a desarrollar una política europea sobre la base de una cooperación intensificada del acuerdo del EEE. Las relaciones con el Reino de Noruega son estrechas y estables y la cooperación con la UE ha recibido un nuevo impulso por parte del Gobierno noruego con la presentación del documento «Norway in Europe 2014-2017». Entre la UE y la Confederación Suiza existen unas relaciones basadas en un sistema muy complejo, que comprende más de 120 acuerdos sectoriales específicos que abarcan un amplio abanico de políticas de la UE, especialmente la participación de Suiza en numerosos aspectos del Mercado interior de la UE. El Gobierno suizo es partidario de seguir con el sistema de los acuerdos sectoriales, pero el Consejo de la UE viene indicando, desde el año 2008, que sería mejor establecer un marco institucional global que regulase las relaciones bilaterales, con el fin de garantizar la homogeneidad y la seguridad jurídica en el Mercado único. Con ello, se quiere cerrar, cara al futuro, la vía de los acuerdos sectoriales específicos.

3. Con respecto a los Estados de pequeña dimensión territorial, el Consejo de la UE, en la reunión del Consejo de Asuntos Generales, del día 16 de diciembre de 2014, adoptó la decisión de autorizar la apertura de negociaciones sobre uno o varios acuerdos de asociación entre la UE y el Principado de Andorra, el Principado de Mónaco y la República de San Marino. No se incluyó el Principado de Liechtenstein en esta decisión, pero sí aparece dentro del Documento: «Conclusiones del Consejo relativas a un mercado único ampliado homogéneo y a las relaciones de la UE con los países de Europa occidental no miembros de la UE». Liechtenstein es un Estado europeo de pequeña dimensión territorial que hace tiempo participa en el mercado interior de la UE a través del EEE, junto con Islandia y Noruega, y destaca por los esfuerzos para incorporar el «acervo» de la UE en el acuerdo EEE. La experiencia hasta el momento presente ha sido positiva y Liechtenstein se ha convertido en un centro no sólo financiero, sino también industrial dotado de centros dinámicos en productos para farmacéuticos, de ingeniería y de alta tecnología.

4. En la citada decisión del Consejo se destacan las relaciones de la UE con los tres Estados de pequeña dimensión territorial calificadas como de nivel elevado en estabilidad y de cooperación. Así mismo, el Consejo se felicita por la intención de los tres Estados de querer desarrollar unas relaciones más estrechas con la UE. Andorra, Mónaco y San Marino han seguido caminos diferentes hasta llegar al momento actual, 
por ello vamos a examinar, brevemente, el caso concreto del Principado de Andorra, que ya poco antes de la Constitución de 1993 optó por una estrategia de acercamiento gradual y progresivo hacia la UE. El proceso de acercamiento a la UE se ha desarrollado en tres fases. La primera tuvo un carácter aduanero y comercial y se concretó en el Acuerdo en forma de canje de notas entre la Comunidad Económica Europea y el Principado de Andorra, de 28 de junio de 1990, en vigor desde el 1 de julio de 1991, que creó una unión aduanera entre Andorra y la CE para los productos industriales. Quedaron excluidos de la unión, pero no del Acuerdo, los productos agrícolas y alimenticios. En 1997 se firmó el Protocolo sobre cuestiones veterinarias, complementario del Acuerdo de 1990. Mencionemos también el Apéndice a las reglas de origen del año 1999, importante para la exportación de productos agrícolas transformados. En la segunda fase Andorra intenta conseguir un nuevo encaje en la UE con la integración de nuevos ámbitos que fueran más allá de las aduanas. Se concretó en el Acuerdo de cooperación entre el Principado de Andorra y la Comunidad Europea, de 15 de noviembre de 2004, en vigor desde el 1 de julio de 2005. También pertenece a esta fase el Acuerdo entre el Principado de Andorra y la Comunidad Europea relativo al establecimiento de medidas equivalentes a las previstas en la Directiva 2003/48/CE del Consejo en materia de fiscalidad de los rendimientos del ahorro en forma de pago de intereses, de 15 de noviembre de 2004, en vigor desde el 1 de junio de 2005. A este último Acuerdo se añadió un Memorándum que hace referencia, entre otras cosas, a la adopción de negociaciones para un acuerdo monetario y para definir un campo de aplicación de la cooperación económica y fiscal más amplio. El Acuerdo monetario entre la UE y el Principado de Andorra fue firmado el 30 de junio de 2011 y entró en vigor el 1 de abril de 2012.

5. La tercera fase se inicia, oficialmente, con la Decisión del Consejo de la UE de autorizar la apertura de negociaciones con los Estados de pequeña dimensión territorial, de 16 de diciembre de 2004, si bien el proceso de aproximación al Mercado interior Europeo comenzó por iniciativa andorrana el 5 de mayo de 2010, con un Documento informal de reflexión, presentado por el Gobierno andorrano a la Comisión Europea, en el que se pedía un nuevo acuerdo que permitiera avanzar en la ampliación de las relaciones con la UE, con el fin de suprimir las fronteras con la Unión respecto del control de mercaderías y aumentar el grado de integración económica. Se pedía, lógicamente, un trato ad hoc sobre ciertos aspectos de las libertades de circulación y establecimiento, porque una aplicación automática del acervo comunitario podría comportar consecuencias problemáticas para un pequeño Estado. Ha habido ya reuniones para revisar el Acuerdo sobre fiscalidad, a iniciativa de la UE, y ya comenzarán en el 2015 las reuniones sobre el Acuerdo de asociación. Ambas negociaciones tienen un contenido diferente y no están interrelacionadas aunque coincidan en el tiempo. Dejemos constancia de que la propuesta de asociación ofrecida por la UE a Andorra, Mónaco y San Marino en relación con el Mercado interior Europeo es un caso único, sin precedentes.

Ramon VIÑAS FARRÉ

Universitat de Barcelona

http://dx.doi.org/10.17103/redi.67.1.2015.4b.03

\section{LA NUEVA LEY 14/2014 DE NAVEGACIÓN MARÍTIMA DESDE LA ÓPTICA DEL DERECHO INTERNACIONAL PRIVADO}

1. La transcendencia y particularidad que el Derecho del transporte marítimo despliega en el comercio internacional constituye el hilo conductor de esta reflexión 
que persigue, desde una dimensión y enfoque internacionalprivatista, identificar diversas cuestiones controvertidas y jurídicamente relevantes que se hallan presentes en el contenido de la nueva Ley de Navegación Marítima adscritas al ámbito del ejercicio efectivo de la actividad de porteador marítimo.

2. La nueva Ley 14/2014 representa sin duda, y pese a aspectos susceptibles de crítica desde nuestra perspectiva de análisis iusinternacionalprivatista, un avance normativo muy significativo, al permitir dotar a nuestro ordenamiento jurídico de un marco legal moderno y sistematizado, que fomenta además una mayor seguridad jurídica y previsibilidad.

Este nuevo texto normativo requiere un examen en profundidad, con el propósito de analizar cómo tratar de proyectar sobre el ámbito internacional las problemáticas específicas que afloran en el sector del Derecho del transporte marítimo europeo e internacional como consecuencia de la interacción de los distintos bloques normativos en presencia, e interesa destacar aquellas instituciones que requieren un tratamiento diferenciado desde la óptica del Derecho internacional privado.

3. Ante las diversas aproximaciones que el Derecho del transporte marítimo permite en lo concerniente a su objeto de estudio, debe siempre abordarse una imprescindible tarea delimitadora que observe la vertiente de Derecho privado correspondiente a nuestra disciplina, sin descuidar otras que indisponiblemente tendrán que ser acometidas con la finalidad de dar una respuesta analítica acorde con las características propias del Derecho internacional privado actual, condicionado por la precisión atributiva del tráfico externo y una sugerente especialización por sectores (véanse a Álvarez Rubio, J. J., Las Lecciones Jurídicas del Caso Prestige: Prevención, Gestión y Sanción frente a la contaminación marina por hidrocarburos, Pamplona, Aranzadi, 2011, pp. 1 y ss.; GonzÁlez CAMPos, J. D., «Diversification, Spécialisation, Flexibilisation et Matérialisation des règles de Droit International Privé», $R$. des $C$., 2002 , t. 287 , pp. 156 y ss.).

La nota de internacionalidad del Derecho del transporte marítimo y la tendencia hacia su uniformidad normativa internacional delimitada hoy por la europeización del Derecho privado tras la entrada en vigor del Tratado de Lisboa y la proyección o dimensión externa de este proceso [BorRÁs, A., «La comunitarización del Derecho internacional privado: pasado, presente y futuro», Cursos de Derecho Internacional de Vitoria-Gasteiz (2001), Vitoria-Gasteiz, Servicio de Publicaciones de la Universidad del País Vasco, 2002, pp. 285-318], refleja claramente una problemática específica en territorio europeo debido a la coexistencia en el sector de bloques normativos diferenciados (FERNÁNDEZ RozAS, J. C., «La comunitarización del Derecho internacional privado y Derecho aplicable a las obligaciones contractuales», RES, 2009, núm. 140, pp. 600 y ss.).

4. La primera conclusión que cabe inferir del contenido normativo de la nueva Ley de Navegación Marítima es que el resultado normativo final se ha visto enriquecido respecto al trabajo previo y apreciable en los anteproyectos y proyectos que precedieron a la ley, y esto queda constatado en una redacción más cuidada y completa de toda la dimensión internacional. Pese a esta valoración global positiva, no cabe obviar que por momentos el legislador parece articular como una especie de «Guadiana normativo» al Derecho europeo, y olvida por momentos incorporar la referencia expresa al Derecho europeo/comunitario.

La nueva ley parece, por momentos, no advertir el transcendental protagonismo que ostenta el bloque normativo europeo para este particular sector comercial. Como 
aporte hermenéutico, debe tenerse en cuenta que no hay referencia alguna al Derecho europeo a lo largo del preámbulo a excepción de la indicación de pertenencia de España al ámbito comunitario europeo, que no Unión Europea, para subrayar que dicha realidad conlleva mayores exigencias en materia de responsabilidad por contaminación marítima; se trata, por tanto, de una escueta referencia a las exigencias que establece el Derecho de la UE en materia de seguros de grandes riesgos y una indicación sobre la aplicación preferente en materia procesal de los Convenios internacionales y las normas de la UE sobre el Derecho interno.

5. El texto carece de una pronta identificación de la magnitud y vocación internacional de sus normas que permita al operador jurídico identificar desde su inicio esta realidad. El artículo primero dedicado al objeto y ámbito de aplicación debiera haber recogido una clara referencia a dicho extremo, sin perjuicio de la referencia a la prelación de fuentes y su interpretación recogida y ubicada en el artículo segundo.

Cabe subrayar la ausencia total de referencia al Derecho europeo comunitario en el título I dedicado a la ordenación administrativa de la navegación, en concreto en los capítulos dedicados al ámbito de aplicación de las normas de policía, el régimen de estancia en aguas interiores marítimas y en puerto y al régimen general de la navegación marítima, donde se establece el articulado relativo a la lucha contra la contaminación y donde hubiese sido necesario incorporar una referencia expresa al bloque normativo europeo.

En este sentido, es muy significativa la ausencia de alusión alguna a la Ley Orgánica del Poder Judicial (art. 22) y al Derecho europeo en la redacción del art. 43, capítulo IV, concerniente al derecho de paso inocente por el mar territorial, sobre el ejercicio de la jurisdicción civil en comparación con el precepto relativo al ejercicio de la jurisdicción penal en el que sí se ha recogido tal previsión.

6. En cuanto al capítulo dedicado a la regulación del contrato de fletamento, cabría resaltar que la apuesta del legislador por respetar la autonomía de la voluntad de las partes permite consolidar una orientación acertada, en contraste con otras previsiones procesales llamativamente restrictivas de la misma. En lo positivo cabe subrayar las disposiciones concernientes a los gastos del fletamento por tiempo y por viaje (art. 204.2), la designación del muelle o lugar de carga (art. 217.1), o incluso el precepto que regula las operaciones de carga y estiba como operaciones conexas transcendentales para el efectivo transporte de las mercancías por vía marítima y la posibilidad de que las partes acuerden a quién corresponde la realización de dichas actividades y la asunción de los riesgos que puedan acontecer (art. 218).

También es necesario resaltar, respecto a la sección dedicada al conocimiento de embarque, el art. 251 de la Ley de Navegación Marítima destinado a la eficacia traslativa del conocimiento de embarque como título valor. De esta manera, habrá que valorar la exigencia que establece la norma sobre la verificación del consentimiento por parte del adquirente respecto de los acuerdos de jurisdicción y arbitraje. Es decir, que con independencia de que la transmisión del conocimiento de embarque produzca idénticos efectos a la entrega de las mercancías sucediendo el adquirente en todos los derechos y obligaciones al transmitente, el adquirente tendrá que dar su consentimiento expreso sobre los acuerdos existentes en materia de jurisdicción y arbitraje según los términos de los arts. 468 y 469. Cuestión que difiere de la consolidada interpretación jurisprudencial del TJUE (STJCE de 19 de junio de 1984, asunto Tilly Russ, 71/83; STJCE de 16 de marzo de 1999, asunto Castelletti, C-159/97; STJCE de 9 de noviembre de 2000, asunto Coreck Maritime GmbH y Handelsveen BV y otros, 
C-387/98) que sólo exige la verificación del consentimiento en aquellos casos en los que, según el Derecho nacional aplicable, el tenedor no haya sucedido al cargador en sus derechos y obligaciones.

7. Otro aspecto que cabría resaltar es la falta de previsión de la ley sobre la entrada en vigor del nuevo RBI bis, que demandaba un ejercicio de prospección futuro no acometido por el legislador, y que parece traerá consecuencias en su aplicación práctica. La Ley de Navegación Marítima recoge expresamente en el capítulo I del título IX ciertas especialidades en materia de competencia judicial internacional, concretamente en el art. 468 (cláusulas de jurisdicción y arbitraje) y en el art. 469 (criterios de atribución de competencia).

El art. 468 recoge una regla referente a los acuerdos atributivos de jurisdicción de carácter expreso que ante la inexistencia de Convenios internacionales aplicables se verá desplazada por el art. 25 del RBI bis relativo a la prórroga de la competencia. Un art. 25 que permite a las partes, con independencia de su domicilio, acordar el sometimiento de sus controversias a los tribunales de un Estado miembro.

La norma contenida en el art. 468 recoge una interpretación restrictiva de la derogatio fori de los Tribunales españoles ante la existencia de un acuerdo atributivo de jurisdicción a un tribunal extranjero o a un arbitraje en el extranjero, advirtiendo de la nulidad de toda cláusula que no haya sido negociada de forma individual y separada al contrato principal (véase DE Miguel Asensio, P. A., "Los acuerdos de jurisdicción en la nueva Ley de Navegación Marítima», 17 de septiembre de 2014, recuperado de http:// pedrodemiguelasensio.blogspot.com.es/2014/10/los-acuerdos-de-jurisdiccion-en-la.html).

En consecuencia, esto supone que para aquellos casos en los que el tribunal o tribunales extranjeros designados por las partes mediante acuerdo atributivo de jurisdicción como competentes para conocer del litigio no estén ubicados en un Estado miembro del RBI bis o no sean parte de un Convenio internacional en vigor en España que contemple o ampare tal posibilidad de autorregulación procesal de las partes, será aplicable el régimen contenido en el mencionado artículo de la Ley de Navegación Marítima, debiéndose entender que si no se cumple con las condiciones exigidas por esta norma en los contratos de utilización de buque o en los contratos auxiliares de navegación, la cláusula del contrato que recoja la sumisión expresa a tribunal extranjero o a arbitraje en el extranjero será nula y se tendrá por no puesta.

En efecto, si esto fuera así, los tribunales españoles entenderán que son competentes para conocer de la controversia suscitada y llegado el caso esto podría suponer un problema de cara a la ejecución de la sentencia y respecto a su validez extraterritorial.

La consagración de la autonomía de la voluntad para la materialización de los acuerdos de elección del tribunal competente, es un debate con enorme interés para nuestra disciplina de Derecho internacional privado, que aflora en el estudio de este particular sector del Derecho del transporte internacional. En este sentido, la visión restrictiva que proyecta el art. 468 supone una limitación de la voluntad de las partes para la elección del foro jurisdiccional que no se sostiene en términos jurídicos, y refleja además una desconfianza hacia la autonomía de las partes y contraviene la consagrada práctica o costumbre y usos del sector. Desde luego, es necesario que el sistema competencial evolucione sin condicionantes hacia criterios de atribución determinados por la autonomía de la voluntad de las partes.

8. Por otro lado, debido a la entrada en vigor para España, el 14 de septiembre de 2011, del Convenio de Ginebra de 12 de marzo de 1999 sobre el embargo preventivo de buques, se mejora, sin duda, la redacción del art. 538 del Anteproyecto de Ley de 
2006 y del art. 501 del Proyecto de Ley del mismo año. Ambos preceptos incorporaban por referencia una disposición convencional que no formaba parte del Derecho interno español para regular el embargo de buque por otros créditos cuando en España todavía era aplicable el Convenio sobre embargo preventivo de buques de 1952. Este Convenio convivió con el actual texto aplicable hasta que la denuncia efectuada por España, el día 28 de marzo de 2012, desplegó sus efectos.

Aun así, la regulación recogida por esta nueva Ley de Navegación Marítima sobre el embargo preventivo de buques no queda exenta en la actualidad de debate jurídico en relación con el art. 31 del RBI sobre medidas provisionales y cautelares (art. 35 RBI bis). Debe tenerse en cuenta que el art. 470 del capítulo II del título IX sobre el embargo preventivo de buques que recoge la naturaleza y regulación de la medida, alude a la medida cautelar del embargo preventivo remitiéndose a la aplicación de lo regulado en el Convenio sobre embargo preventivo de buques de 1999, a lo dispuesto en la propia ley y, supletoriamente, a lo establecido en la LEC, sin referencia alguna a la LOPJ, ni al Derecho comunitario (RBI y RBI bis). Ausencia nuevamente sorprendente si tenemos en cuenta que en las materias incluidas dentro del ámbito de aplicación del RBI sus disposiciones desplazan a las normas contenidas en el Derecho interno (véase ARENAS GARCíA, R., "Las medidas provisionales y cautelares en el Reglamento Bruselas I: de la regulación actual a la regulación proyectada», La Ley, 2011, núm. 7601).

La doctrina ha cuestionado y resaltado si la firma del Convenio sobre embargo preventivo de buques de 1999 por España, sin haber realizado reserva alguna respecto a la aplicación del criterio de la lex fori como criterio atributivo de competencia para conocer sobre el fondo del asunto (art. 7), podría o no suponer un incumplimiento del Derecho comunitario afectando incluso en lo concerniente al reconocimiento y ejecución de las decisiones judiciales en materia civil y mercantil (véase QuiRós DE SAS, A., "El nuevo régimen del embargo preventivo de buques en el Derecho español», Actualidad Jurídica Uría Menéndez, 2012, núm. 32, pp. 137-141).

9. En definitiva, el resultado de la nueva Ley de Navegación Marítima es satisfactorio al permitir una regulación moderna, depurada y elaborada con un alto grado de detalle. No obstante, habría algunos aspectos que hubiesen requerido un ejercicio de prospección futura, y otros que demandaban un mayor acierto en cuanto a la importancia del Derecho internacional privado comunitario como marco jurídico de carácter institucional, previsible, equilibrado y sencillo.

Además, en un sector tan complejo como el del Derecho del transporte marítimo internacional es muy positivo, sin perjuicio de las singularidades presentes en cada una de las modalidades de contratación, que un texto de estas características sea respetuoso con la libertad contractual reconocida tradicionalmente a las partes en este ámbito.

Unai BeLINTXON MARTín

Prof. Asociado de Derecho internacional privado

Universidad Pública de Navarra

http://dx.doi.org/10.17103/redi.67.1.2015.4b.04

\section{24. ${ }^{a}$ REUNIÓN DEL GRUPO EUROPEO DE DERECHO INTERNACIONAL PRIVADO (FLORENCIA, 19 A 21 DE SEPTIEMBRE DE 2014)}

1. La 24. ${ }^{\mathrm{a}}$ reunión del Grupo Europeo de Derecho Internacional Privado (en adelante, GEDIP) tuvo lugar en Florencia (Italia), los días 19 a 21 de septiembre de 2014 
en la "Villa Finaly», un magnífico edificio propiedad en la actualidad de las 13 Universidades de París, como resultado de la donación que les hizo su propietario, en la que se celebran numerosas reuniones de carácter científico (detalles en www.villafinaly.sorbonne.fr). En esta ocasión, la organización de la reunión corrió a cargo de los Profs. C. Kessedjian (Universidad Panthéon-Assas, Paris II) y E. Pataut (Universidad Panthéon-Sorbonne, Paris I). Como viene siendo habitual, los trabajos se dividieron en varios bloques, dedicados a la información sobre los trabajos de la Unión Europea y de la Conferencia de La Haya de Derecho internacional privado, a la información sobre la jurisprudencia del Tribunal Europeo de Derechos Humanos, a temas puntuales de interés y a las propuestas sobre los trabajos en curso en el GEDIP.

2. En el bloque relativo a la información sobre la Unión Europea, intervino en primer lugar el Prof. Ch. Kohler sobre «Actualidades del Derecho de la Unión», centrándose esencialmente en dos temas, el futuro tras el término del Programa de Estocolmo en diciembre de 2014 y la aplicación del Reglamento Bruselas II bis y las perspectivas de revisión.

En lo que se refiere al futuro tras el fin del Programa de Estocolmo, realizó algunas consideraciones en torno a la Comunicación de la Comisión conteniendo la «Agenda de Justicia de la UE para 2020» [Documento COM(2014) 144 final y, sobre el mismo, nota de información de M. GuZMán, en REDI, 2014, núm. 1, pp. 321 y ss.] y resaltando la importancia del apoyo dado por el Consejo celebrado en junio, tema en el que también incidió la representante de la Comisión Europea, la Sra. K. Vandekerkhove, destacando las líneas estratégicas y políticas de la Comisión en su nueva estructura. Asimismo, se refirió a los proyectos concretos e inmediatos más destacados y, en particular, a la revisión del Reglamento 1346/2000 en materia de insolvencia, que considera concluirá en breve. Y anunció, también, la posibilidad de que se publique en breve la propuesta relativa a la revisión del art. 14 del Reglamento Roma I y la inclusión de una regla sobre ley aplicable a la oponibilidad a terceros de las cesiones y prendas de créditos.

En lo que se refiere a la revisión del Reglamento 2201/2003 (Bruselas II bis), el Prof. Kohler señaló que, en conjunto, puede hablarse de un cierto grado de satisfacción, si bien hay problemas derivados del ámbito distinto de este Reglamento y del Reglamento Roma III, de las cuestiones que se plantean cuando hay relación con terceros Estados y del reconocimiento y ejecución de sentencias, tema en el que también incide la Sra. Vandekerkhove, sobre la base del informe ya realizado y a la espera de los resultados de la consulta pública. En este caso, debe mencionarse también el documento presentado por el Sr. Hans Van Loon en relación con la revisión del Reglamento Bruselas II bis y que contiene algunas reflexiones personales para una mejor articulación del régimen de ley aplicable en materia de responsabilidad parental y para una mejor operatividad de las disposiciones de dicho Reglamento que completan el Convenio de La Haya de 1980 en materia de aspectos civiles de la sustracción internacional de menores.

3. Es también el Sr. Hans Van Loon, en su condición de ex Secretario General de la Conferencia de La Haya de Derecho internacional privado, quien informa sobre las actividades de la Organización en el último año. Destaca el aumento del número de miembros de la Conferencia y también el aumento del número de firmantes de diferentes Convenios, destacando el interés de las ratificaciones o adhesiones al Convenio de 1996 sobre protección de niños y al Convenio de alimentos de 2007. Igualmente señala la importancia de la adhesión de Japón al Convenio de 1980 y el problema de la aceptación de las adhesiones al mismo por los Estados miembros de la Unión Europea, un tema entonces pendiente del dictamen del Tribunal de Justicia de la Unión 
Europea (ahora resuelto con el Dictamen 1/13, de 14 de octubre de 2014; comentario de S. Álvarez en esta misma Revista, pp. 241 y ss. y de A. Borrás, en La Ley Unión Europea, núm. 21, diciembre de 2014, pp. 42 y ss.). Tras hacer referencia a los avances en América, a los trabajos de la nueva Oficina de Hong Kong y a la nueva frontera que representa África en relación con los Convenios de La Haya, se refiere a la situación del Proyecto de ley aplicable a los contratos, el primer texto de la Conferencia de naturaleza no obligatoria y a los trabajos en materia de reconocimiento de sentencias (denominado normalmente "proyecto Judgments»), estando prevista en el mes de octubre una reunión del Grupo de Trabajo en Hong Kong.

4. Como viene siendo habitual, el Sr. P. Kinsch informó sobre las sentencias del Tribunal Europeo de Derechos Humanos dictadas en el último año, más relevantes en relación con el Derecho internacional privado. En este caso, se refiere en primer lugar a una importante sentencia en materia de nombre, la Sentencia Henry Kismoun c. Francia, de 5 de diciembre de 2013 que, en realidad, implica una universalización de la jurisprudencia en los famosos asuntos García Avello y Grunkin-Paul. En efecto, se trata de un caso en que el requirente, de madre francesa y padre argelino, es registrado en el momento de su nacimiento en Francia con el nombre de Christian Henry. Abandonado por la madre, es recogido por su padre, que lo lleva a vivir a Argelia, donde se le registra con el nombre de Chérif Kismoun. Pasados los años, vuelve a Francia, donde sigue registrado por el nombre antiguo. Solicita un cambio de nombre que le es denegado, lo que el TEDH considera contrario a los intereses del requirente.

El segundo bloque se refiere al conflictivo tema de los contratos internacionales de maternidad por sustitución (o vientres de alquiler). Además de una decisión de 8 de julio de 2014 de menor interés ( $D$. y otros $c$. Bélgica), destacan las Sentencias de 26 de junio de 2014 en el asunto Mennesson c. Francia y Labassee c. Francia. Se trata del rechazo a transcribir las actas de nacimiento relativas a niños nacidos de esta forma en los Estados Unidos, con padre biológico francés. El Tribunal de Casación francés aplicó con rigor la excepción de orden público en razón de la prohibición del Derecho francés a este tipo de maternidad por sustitución, pero el TEDH adopta una posición más flexible, entendiendo que hay una violación de los derechos del niño al no reconocer la filiación biológica respecto al padre.

El tercer bloque se refiere al reconocimiento y ejecución de sentencias extranjeras, entendiendo que hay violación del derecho al proceso equitativo en los casos de ineficacia del proceso de ejecución o del plazo excesivamente largo para la ejecución. Éste es el caso de la Sentencia de 7 de noviembre de 2013, Matrakas e.a. c. Polonia y Grecia y de la Sentencia de 15 de julio de 2014, Panetta c. Italia, en ambos casos en relación con el Convenio de Nueva York de 1956 en materia de alimentos. Otro caso, la Sentencia de 25 de febrero de 2014, Avotins c. Letonia, se refiere al Reglamento Bruselas I, ya que se trata de la violación de los derechos humanos en un caso en que la sentencia extranjera a ejecutar ha violado las garantías del proceso equitativo, en un supuesto en que no sirven los antecedentes en el asunto Pellegrini.

El cuarto y último bloque se refiere a la cooperación internacional en materia de sustracción de menores y, además de una serie de decisiones en las que se muestra la compatibilidad del Convenio de La Haya de 1980 con la Convención Europea de Derechos humanos, destaca la importante sentencia de la Gran Sala de 28 de noviembre de 2013, en el asunto $X$. c. Letonia, tras una sentencia de la Sala 3. ${ }^{a}$, de 13 de diciembre de 2011, que consideró que fue precipitado el retorno de Letonia a Australia con el padre. La nueva sentencia de la Gran Sala entiende que hay insuficiente motivación de la decisión que rechaza la causa de no retorno, lo que lo hace contrario al art. 8 del 
$\mathrm{CEDH}$, ya que la madre ha sido objeto «de una injerencia desproporcionada en su derecho al respeto de su vida familiar, no habiéndose cumplido las exigencias procesales inherentes al art. 8 del Convenio en el proceso de decisión en el Derecho interno».

5. A dos temas puntuales de interés se refirieron las intervenciones del Prof. M. Bogdan y del Prof. S. Symeonides. El Prof. M. Bogdan realizó una intervención sobre las relaciones entre el Reglamento 606/2013, de 12 de junio, relativo al reconocimiento mutuo de medidas de protección en materia civil ( $D O$ L 181, de 29 de junio de 2013) y la Directiva 2011/99/UE, de 13 de diciembre, sobre la orden europea de protección ( $D O$ L 338, de 21 de diciembre de 2011), dado que se plantean problemas de posible superposición entre ambos textos, puesto que hay problemas de delimitación, dado que se ocupan de temas civiles y penales. En el animado coloquio que siguió a la intervención se pusieron de relieve las razones políticas que condujeron a tener dos documentos distintos, lo que resulta claramente de los Considerandos de los textos y que tienen como resultado dificultades para comprender la relación entre el Reglamento y la Directiva.

Por su parte, el Prof. S. Symeonides se ocupó del tema «Codifying Choice of Law Around the World» que en el programa original tenía el subtítulo de "Lessons by, and for, the EU» pero en la exposición final, acompañada de un animado power point, se convirtió en "The Last Fifty Years», refiriéndose a los años comprendidos entre 1962 y 2012. A lo largo de su exposición se refiere a las Codificaciones internas, que alcanzan el número de 94, y a los Convenios concluidos por diversas Organizaciones internacionales (como UNCITRAL, Mercosur o la Conferencia de La Haya), así como el impacto de la integración europea. Con estos elementos, se fija esencialmente en el impacto que ha tenido en el ámbito de la responsabilidad extracontractual y en el de los contratos, en particular en relación con el papel de la Autonomía de la voluntad.

6. La parte esencial (y más larga) de la reunión se dedicó al tema de la ley aplicable a las sociedades, tomando como base el documento y texto articulado presentado por el Subgrupo integrado por los Profs. Stefania Bariatti, Michael Bodgan, Trevor Hartley, Monika Pauknerova, Kurt Siehr y Teun Struycken, siendo su Presidente F. J. Garcimartín.

En dicho documento: i) se justificaba la necesidad de un instrumento normativo en ese sector; ii) se resumía la jurisprudencia del TJUE pertinente (Daily Mail, Centros, Überseering, Inspire Art, Cartesio o Vale, principalmente), y iii) se proponía un borrador de Reglamento. El contenido de este borrador se estructuraba sobre cuatro grandes apartados. En primer lugar, dos artículos relativos a su ámbito de aplicación, donde se optaba por una solución muy amplía, comprendiendo tanto las sociedades mercantiles como civiles, de responsabilidad limitada o de personas, y con alcance universal. En segundo lugar, el establecimiento de una regla general de determinación de la lex societatis basada en los llamados «modelos de constitución», esto es, la ley aplicable a una sociedad es la ley del país bajo la cual la hayan constituido los socios. En tercer lugar, la fijación del ámbito de aplicación de la ley designada conforme a esa regla, donde se optaba por un principio de aplicación integral salvo dos conexiones especiales en materia de capacidad y responsabilidad. En cuarto lugar, se incluían normas relativas al cambio de lex societatis o traslado de sede. Y, por último, un elenco de reglas relativas a los problemas de aplicación: reenvío, orden público, remisión a un sistema pluri-legislativo y leyes de policía.

Las discusiones dentro del Grupo sobre este documento de trabajo se centraron, principalmente, en los siguientes aspectos. En primer lugar, hubo acuerdo en la necesidad de un instrumento sobre la ley aplicable a las sociedades y otras personas jurídi- 
cas. La jurisprudencia del Tribunal de Justicia, aunque ha resuelto algunos problemas fundamentales, se consideró insuficiente para ofrecer un marco legal adecuado y exhaustivo sobre una cuestión tan relevante para el buen funcionamiento del mercado interior. Y asimismo, hubo bastante consenso sobre los aspectos fundamentales de dicho instrumento, en particular: i) su carácter universal, esto es, su aplicación tanto a sociedades europeas como de terceros Estados; ii) la adopción de un modelo de incorporación - frente a un modelo de sede real- como regla general para identificar la ley aplicable; iii) la extensión de ésta tanto a las relaciones internas de la sociedad, esto es, socios entre sí y socios con administradores, como a sus relaciones externas, esto es, capacidad y responsabilidad, y iv) por último, la inclusión de normas sobre el cambio de ley aplicable.

No obstante, y al margen de los comentarios relativos a la estructura externa del futuro instrumento y de redacción técnica, se puso de manifiesto la necesidad de seguir trabajando en algunos extremos como, por ejemplo, la delimitación de este texto y otros instrumentos europeos —en particular, el Reglamento Roma I-, la procedencia de refinar el juego de la regla general cuando nos encontramos ante sociedades que no se han incorporado formalmente bajo ningún ordenamiento (p. ej., las sociedades civiles con personalidad jurídica), la necesidad de introducir una cláusula de escape a favor de los vínculos más estrechos o la adopción de una conexión especial sobre la ley aplicable a la responsabilidad de los miembros y directivos de una sociedad. Finalmente se acordó continuar los trabajos del mencionado subgrupo con el objeto de presentar una nueva propuesta en la próxima reunión.

7. Además de la continuación de los trabajos referentes a la ley aplicable a las sociedades a que se acaba de hacer referencia, el subgrupo, creado en Lausanne en 2013 para tratar del papel de la nacionalidad como criterio de conexión en los instrumentos europeos, presidido por el Prof. E. Pataut, amplía su mandato para ocuparse de la modificación del Reglamento Bruselas II bis, quedando integrado por los Profs. Andrea Bonomi, Alegría Borrás, Hélène Gaudemet-Tallon, Christian Kohler, Rui M. Moura Ramos y Paul Lagarde.

La próxima reunión del Grupo tendrá lugar en Luxemburgo, los días 18 a 20 de septiembre de 2015.

Alegría BorRÁs y Francisco J. GARCIMARTíN Universidades de Barcelona y Autónoma de Madrid http://dx.doi.org/10.17103/redi.67.1.2015.4b.05

\section{CELEBRACIÓN DEL 50. ${ }^{\circ}$ ANIVERSARIO DE LA RIVISTA DI DIRITTO INTERNAZIONALE PRIVATO E PROCESSUALE (MILÁN, 23 DE OCTUBRE DE 2014)}

1. El 23 de octubre de 2014 tuvo lugar un Convengo titulado «Per un nuovo Diritto internazionale privato», para celebrar el $50 .^{\circ}$ aniversario de la Rivista di Diritto internazionale privato e processuale, que tuvo lugar en el Aula Magna de la Università degli Studi di Milano con asistencia de unas 200 personas. El acto se ha incluido en los actos de celebración del $90 .^{\circ}$ aniversario de la Universidad de Milán.

La inauguración formal corrió a cargo del Prof. Fausto Pocar, que ha estado siempre presente en la Rivista. En su intervención señaló que precisamente ese día salía el tercer número de 2014, recordando que fue en esas mismas fechas de 1964 cuando apareció su primer número. Resaltó que se trató siempre de una revista abierta a to- 
dos los estudiosos, independientemente de escuelas y tendencias, algo no tan evidente en aquellos momentos, y de una revista abierta en cuanto a las materias, puesto que ya entonces señalaba la importancia del Derecho comunitario para el Derecho internacional privado. Finalmente, recordó que el siglo xx concluyó con la promulgación de la Ley 218/1995 de Derecho internacional privado, que menciona los Convenios internacionales, pero no los instrumentos comunitarios y de ahí que, ahora que el siglo XXI ha visto la comunitarización del Derecho internacional privado, el legislador ha de tomar postura para adaptar la Ley de 1995 a ese nuevo escenario normativo. Ese es, pues, el objetivo del Convegno.

El acto contó también con la intervención de los Directores del Departamento de Estudios internacionales, jurídicos e histórico-políticos y de Derecho público italiano y supranacional y de la representante de la Editorial Walters Kluwer, que resaltó la publicación digital de la Revista precisamente desde este año, que permite su consulta online, en tablet y en smartphone.

2. A lo largo del día se celebraron cuatro mesas redondas, la primera dedicada a las opciones de fondo de la Ley 218/1995 y las cuestiones generales, la segunda dedicada a las materias relativas al estatuto personal, la tercera dedicada a las obligaciones contractuales y extracontractuales y la cuarta al Derecho procesal civil internacional. En todas ellas hubo un moderador, diversos ponentes y, tras el coloquio, unas consideraciones finales por algún profesor estrechamente vinculado a la propia Revista. Al término de la Jornada, el Prof. Fausto Pocar realizó algunas consideraciones finales en torno a los temas abordados y las posibles actuaciones. En ellas manifestó su satisfacción como Director responsable y el hecho de que participen los Directores de la Rivista (Tullio Treves, Roberta Clerici, Stefania Bariatti, Sergio M. Carbone, Andrea Giardina, Riccardo Luzzatto y Franco Mosconi). En cuanto a las posibles soluciones a los temas planteados y al contenido de los instrumentos comunitarios, resaltó las excelentes soluciones que fueron propuestas en su día por el GEDIP.

3. La primera mesa redonda, moderada por el propio Prof. Fausto Pocar, se dedicó a examinar algunas opciones de fondo de la ley italiana y las cuestiones generales. La primera intervención corrió a cargo del Prof. Roberto Baratta, profesor de la Universidad de Macerata y de la Universidad LUISS de Roma y durante años consejero jurídico de la REPER de Italia en Bruselas, que resaltó la necesidad de la modernización del Derecho internacional privado con un enfoque transversal, en que la «soberanía absoluta» del Estado quiebra con la participación en los instrumentos comunitarios, por lo que el art. 2 de la Legge tiene un mero valor narrativo y necesita de mayor apertura. Destaca el significado y alcance de la integración en el espacio jurídico europeo, con especial mención del Dictamen 1/13, de 14 de octubre de 2014, y recordando que Italia fue el único Estado miembro que se manifestó a favor de la competencia externa exclusiva. Finalmente, señaló diversos aspectos en los que se debe avanzar, citando para ello la abundante jurisprudencia del Tribunal de Luxemburgo.

La siguiente intervención corrió a cargo del Sr. Hans Van Loon, ex Secretario General de la Conferencia de La Haya de Derecho internacional privado, que inició su intervención mencionando el libro de S. Symeonides, Codifying Choice of Law Around the World: The Last Fifty Years, Willamette University, 2014, en que se destacan los últimos cincuenta años como los más productivos desde la perspectiva de las codificaciones nacionales, pero que el Derecho internacional privado moderno ha de mostrar los vínculos con los convenios internacionales y los instrumentos comunitarios. En esta situación, su intervención aborda, en primer lugar, la regulación internacional y la supranacional como límite a la legislación nacional; en segundo lugar, la forma 
de articular las distintas fuentes, teniendo en cuenta la diferencia entre los temas de ley aplicable y los temas de competencia judicial internacional, reconocimiento y ejecución de decisiones; en tercero y último lugar, la forma de abordar las sentencias extranjeras que han de producir efecto en el orden interno, con especial referencia a la jurisprudencia del Tribunal de Justicia y del Tribunal Europeo de Derechos Humanos.

El tercer interviniente en esta mesa redonda fue el Prof. Marc Fallon, de la Universidad de Louvain-la-Neuve y actualmente Presidente del GEDIP. Su intervención tuvo por objeto señalar algunas de las diferencias más destacadas entre la Ley italiana y la Ley belga de Derecho internacional privado de 2004. En cuanto a la parte general, destaca las similitudes entre ambas, salvo en relación con la norma italiana en materia de reenvío, ampliamente criticada en ésta y en otras intervenciones. Señala el papel de la autonomía de la voluntad y la forma en que se incorporan los distintos instrumentos de la Unión, teniendo en cuenta la materia que abordan y el alcance de las distintas disposiciones.

El Prof. Tullio Treves, de la Universidad de Milán, formuló algunas consideraciones finales, haciendo especial mención al fundador de la Rivista, el Prof. Mario Giuliano.

4. La segunda mesa redonda estuvo dedicada a los temas de estatuto personal, familia y sucesiones y fue moderada por la Prof. ${ }^{a}$ Roberta Clerici, de la Universidad de Milán, que destacó la necesidad de sustituir determinadas normas internas, recordando que Italia será el último Estado miembro de la Unión Europea en ratificar el Convenio de La Haya de 1996.

La primera intervención corrió a cargo de la Prof. a Ilaria Viarengo, también de la Universidad de Milán, que se ocupó del tema de los alimentos en relación con el art. 45 de la Legge, que aún sigue mencionando el Convenio de La Haya de 1973 en vez del Protocolo de La Haya de 2007, cuya vigencia hace inútil, a su juicio, cualquier otra norma de conflicto.

La segunda intervención correspondió al Prof. Luigi Fumagalli, de la Universidad de Milán, que se refirió al tema de las sucesiones, con especial atención al art. 46 de la Legge en lo que se refiere a la ley aplicable y a los efectos del Reglamento. En cuanto a los aspectos procesales, destaca el hecho de que el Reglamento no deja espacio para una delimitación discrecional y que, por tanto, sustituye completamente al art. 50 de la propia Ley.

A continuación, la Prof. a Constanza Honorati de la Universidad de Milano-Bicocca, se refirió a los temas relativos a la filiación, destacando que es el único caso en que hay una normativa nueva en la Legge (arts. 33 y ss.), como consecuencia del Decreto legislativo núm. 154/2013, de 28 de diciembre, que se aplica a partir del 7 de febrero de 2014. Destaca la diferencia entre la rigidez de la normativa italiana y la flexibilidad del Reino Unido, que estaría más próximo a la actitud del Tribunal Europeo de Derechos Humanos y su reciente jurisprudencia (al respecto, véase la nota de A. Borrás y F. J. Garcimartín sobre la reunión del GEDIP en Florencia, en septiembre de 2014, en esta misma Revista y crónica, pp. 344-348).

El Prof. Carlo Rimini, de la Universidad de Milán, interviene como abogado de temas de Derecho de familia, para explicar su experiencia sobre cómo se vive en la vida práctica ante los tribunales la situación actual. Señala el difícil diálogo entre los instrumentos, destacando la fragmentación que se produce en el ámbito del Derecho de familia, comparándolo con lo que ocurre en una mesa de billar. Destaca que, desde su perspectiva de abogado italiano, se encuentra con más problemas, ya que las nor- 
mas no están pensadas para llevar todos los temas juntos y, en particular, en el caso de disolución del matrimonio, aparecen juntos.

Finalmente, interviene la autora de esta nota, invitada especialmente para hablar de temas de Derecho de familia, comparando la situación española y la italiana, aunque, como se indicó, muchas de las observaciones que se hicieron podrían trasladarse a los temas tratados en las demás mesas redondas. En una primera parte se señalaron dos importantes diferencias: el hecho de que en España no hay una Ley de Derecho internacional privado y el hecho de que España es un ordenamiento plurilegislativo. En una segunda parte se hizo referencia a la situación actual, particularmente en el título preliminar del Código Civil, y a los proyectos en marcha, con especial mención al proyecto de Ley de protección de la infancia.

Las consideraciones finales de esta mesa fueron realizadas por el Prof. Franco Mosconi, de la Universidad de Pavía, que destacó la evolución de la familia y la reacción de las legislaciones internas, en particular, en Suiza y en Canadá.

5. La tercera mesa redonda estuvo dedicada a las sociedades, a las obligaciones contractuales y a las obligaciones extracontractuales, siendo el moderador el Prof. Riccardo Luzzatto, de la Universidad de Milán.

La primera intervención corrió a cargo del Prof. Peter Kindler, de la Universidad de Múnich, que se refirió a la lex societatis y a la diferencia entre los Estados que adoptan el sistema de la sede real y aquellos que adoptan el sistema de la constitución, recordando toda la jurisprudencia del Tribunal de Justicia y la conveniencia de tomar en consideración el concepto contenido en el Reglamento 1346/2000 en materia de quiebra (sobre este tema, véase la nota sobre los trabajos del GEDIP en esta materia, op. cit.).

También a un tema de Derecho de sociedades se refiere el Prof. Domenico Damescelli, de la Universidad del Salento y notario, que trata de la transferencia de sede y al hecho de que se modifique o no la ley aplicable, algo que depende del Derecho aplicable. Se refiere, en particular, a la necesidad de modificar el art. 25 de la Legge, sin perjuicio de que también debieran modificarse otras disposiciones, en particular en el Código Civil.

El Prof. Ruggiero Cafari Panico, de la Universidad de Milán, se refiere específicamente a los contratos de trabajo y a los tribunales laborales, en relación con el art. 57 de la ley italiana. Tras un examen de las normas relevantes del Derecho de la Unión Europea y del papel del Tribunal de Justicia, se ocupa también de la conveniencia de extender las soluciones de estos últimos a las relaciones con terceros países.

La Prof. ${ }^{\text {a }}$ Cristina Campiglio, de la Universidad de Pavía, se ocupa de las obligaciones extracontractuales en general y se centra en la jurisprudencia reciente del Tribunal de casación italiano, con especial mención a una reciente sentencia en un procedimiento que ha durado veinte años en relación con las consecuencias lamentables de un accidente de caza que ocurrió en 1994. También presta atención a las exclusiones del Reglamento Roma II. También a las obligaciones extracontractuales se refiere la intervención de Paola Ivaldi, de la Universidad de Génova, que se centra en los daños marítimos, para entender que se aplica el Reglamento Roma II.

Tras la variedad de temas tratados en esta mesa redonda, el Prof. Andrea Giardina, de la Universidad de Roma «La Sapienza» formula sus conclusiones generales.

6. La cuarta y última mesa estuvo dedicada al Derecho procesal civil internacional y fue moderada por el Prof. Sergio Maria Carbone, de la Universidad de Génova, que recordó que precisamente en esta materia se encuentra el origen del Derecho 
internacional privado de la Comunidad Europea. Lamentablemente, el retraso acumulado hizo que esta última mesa fuera más breve que las anteriores.

La primera intervención corrió a cargo del Prof. Francesco Salerno, de la Universidad de Ferrara, que se refirió a los efectos de los instrumentos de la Unión Europea en el ámbito del reconocimiento, subrayando la excesiva jurisprudencia del Tribunal Supremo italiano en materia de forum necessitatis.

El Prof. Alberto Malatesta, de la Universidad Carlo Cattaneo-LIUC, se ocupó de la litispendencia, con especial referencia al actual art. 7 de la Ley italiana de Derecho internacional privado y el posible contenido de la nueva norma.

Por su parte, la Prof. a Francesca Villata, de la Universidad de Milán, habló de la autonomía de la voluntad en el Convenio de Bruselas y en el Reglamento Bruselas I, para plantearse, finalmente, la posibilidad de elegir la ley aplicable a la validez formal de la cláusula de elección de foro, relacionando el tema con el Convenio de La Haya sobre acuerdos de elección de foro.

La Prof. ${ }^{a}$ Lidia Santini, de la Universidad de Milán, se ocupó de la competencia para la adopción de medidas cautelares, señalando la necesidad de modificar el art. 10 de la Legge.

Finalmente, intervino el Sr. Mario Dusi, Presidente del CRINT, instituto que se ocupa de la cooperación internacional en el Colegio de Abogados y que señaló algunos detalles de la necesidad de esta colaboración.

Las conclusiones de esa mesa corrieron a cargo de la Prof. a Stefania Bariatti, de la Universidad de Milán, que, tras manifestarse no partidaria de la reciprocidad, señaló la necesidad de modificar e introducir flexibilidad en la Legge, un ejercicio para el que considera que aún no están preparados.

7. En conjunto, el Convegno merece una valoración muy positiva, teniendo en cuenta dos elementos. El primero, por haber sido consagrado a algo tan importante como la necesaria modificación de las normas internas de Derecho internacional privado, en un momento en que la comunitarización avanza. El segundo, por el mismo hecho de la celebración del $50 .^{\circ}$ aniversario de la Rivista que se valora especialmente desde esta Revista, que conoce el esfuerzo que ello significa, por haber superado ya los sesenta años de vida.

Alegría BorRás

Universidad de Barcelona

http://dx.doi.org/10.17103/redi.67.1.2015.4b.06

\section{DECISIÓN DE LA HIGH COURT DE LONDRES, FAMILY DIVISION, RELATIVA A LA ATRIBUCIÓN FRAUDULENTA DE COMPETENCIA A LOS TRIBUNALES INGLESES EN CIENTO OCHENTA CASOS DE DIVORCIO}

1. Mediante Decisión de 30 de septiembre de 2014 [In the matter of 180 Irregular Divorces (2014) EWFC 35; que puede consultarse en http://www.judiciary.gov.uk/judgments/rapisarda-v-colladon/], el presidente de la Family Division de la High Court de Londres se pronuncia respecto de 180 casos de divorcio, todos ellos solicitados (entre agosto de 2010 y julio 2012) por nacionales italianos ante los tribunales de diferentes condados de Inglaterra y Gales. 
La tramitación conjunta de estos casos deriva de su común irregularidad, ya que, como indica la Decisión (§ 9), en todos ellos la competencia judicial de los tribunales ingleses se basaba en la supuesta residencia habitual en Inglaterra de uno de los cónyuges: en la mayoría de los casos del demandante durante el periodo de un año y en la minoría del demandado. De este modo, la competencia les quedaba atribuida sobre la base del foro recogido, respectivamente, en el guión quinto o guión tercero del art. 3.a) del Reglamento «Bruselas II bis» - Reglamento 2201/2003, de 27 de noviembre, sobre competencia judicial, reconocimiento y ejecución de resoluciones judiciales en materia matrimonial y de responsabilidad parental, por el que se deroga el Reglamento (CE) 1347/2000 - [como indica la Decisión (§§ 8 y 9), en virtud de la Sección 5 (2) Domicile and Matrimonial Proceedings Act 1973, modificado de acuerdo con la normativa europea].

Otro aspecto común en todos los supuestos es el relativo a la causa de divorcio. Como señala la Decisión (§ 11), de entre las posibles causas que permiten acordar un divorcio al tribunal inglés (Sección 1. ${ }^{\mathrm{a}}$, Matrimonial Causes Act 1973), en todas las solicitudes de divorcio se alega la misma por el demandante, que exige la aceptación por el demandado, relativa a la ruptura irreversible del matrimonio acreditada por el hecho de la ausencia de convivencia entre los cónyuges durante un periodo continuado de, al menos, dos años inmediatamente anteriores a la interposición de la demanda. Pero es más, la ausencia de oposición del demandado fue también esencial para que se beneficiaran del procedimiento especial que permite un pronunciamiento rápido de divorcio, articulado sobre la base de la declaración jurada del solicitante, si bien faculta al tribunal para que cualquier parte en el procedimiento facilite la información adicional que considere necesaria (§ 12). Esta información adicional fue solicitada posteriormente, una vez descubierto el fraude, identificado a finales de febrero de 2012 (§ 59), inmediatamente notificado al órgano competente para intervenir en estos supuestos (Queen's Proctor, Matrimonial Causes Act 1973, § 13). Comenzaba así la investigación policial mediante la que se descubre que, en todos los casos, la dirección indicada en Inglaterra, ya fuera la del demandante o demandado (según el caso), era idéntica (Flat 201, 5 High Street, Maidenhead, SL6 1JN) y falsa, ya que como se constata, correspondía a un buzón de correos de una serie ubicada en locales comerciales ( $\S \S 32$ y 34). Detrás de este engaño se descubre la existencia de una persona, esencial para la operación (the moving spirit, § 49), que se lucraba de la misma (el coste total oscilaba entre 3.750 y 4.700 euros). En definitiva, como indica la propia Decisión, los tribunales ingleses fueron inducidos por fraude a la aceptación de la competencia para conocer de las demandas de divorcio, motivo que considera como fundamento, de acuerdo con la jurisprudencia que examina (§§ 18 a 28), de la posible anulación de las sentencias dictadas por los tribunales ingleses por ser el resultado de un procedimiento fraudulento desde el principio ( $\$ \S 29$ y 35). De este modo, tras la solicitud a las partes de información adicional en las correspondientes audiencias - la primera el 30 de octubre de 2013, y otra audiencia final (9 y 10 de abril de 2014) (§§ 66 a 74) — la Decisión considera que procede la desestimación de la demanda en relación con las solicitudes de divorcios no resueltos (70), así como la anulación de todas las sentencias, fuesen provisionales (18) o firmes (91) (§§ 75 a 83), si bien con una específica consideración del caso Rapisarda v. Colladon ( $\$ \S 84$ a 97) para llegar a la misma solución (§ 97).

2. Todo lo anterior permite constatar que el asunto abordado por esta Decisión se refiere a ¡180! casos de forum shopping fraudulento y concertado entre los cónyuges. En todos ellos se aprecia que se trata de situaciones puramente internas que devienen internacionales mediante un fraude que implica a ambos cónyuges, realizado a tra- 
vés de la manipulación (desplazamiento ficticio) de la circunstancia de la residencia habitual de los foros del Reglamento «Bruselas II bis», con el objetivo de atribuir la competencia a los tribunales ingleses y así obtener, mediante el procedimiento especial previsto para los casos en que no existe oposición del demandado, un pronunciamiento rápido de divorcio y sobre la base de la ley inglesa aplicable.

Este objetivo, unido a la común nacionalidad italiana de los cónyuges, permite entender que la finalidad última del fraude era evitar la aplicación de la ley italiana, que hubiera resultado aplicable en ausencia de la manipulación y, con ella, el periodo previo de separación que impone para los supuestos más frecuentes de divorcio [art. 3.2.b) de la Ley 898/1970, Disciplina dei casi di scioglimento del matrimonio].

3. Ahora bien, la consolidación del resultado pretendido mediante el fraudulento desplazamiento de la situación se produciría al obtener el reconocimiento en Italia de la sentencia inglesa de divorcio, que podría haber sido solicitado a través del mismo Reglamento «Bruselas II bis». Un reconocimiento que, en atención a su objetivo de la libre circulación de las decisiones de divorcio, está presidido en este texto por el carácter de la agilidad basada en la confianza mutua entre los tribunales de los distintos Estados miembros (cdo. 21). Pues bien, la articulación de esta confianza como base del reconocimiento de las decisiones arranca, y éste es su principal eje, del presupuesto de la comprobación de la competencia por el tribunal ante el que se plantea la demanda de divorcio (art. 17), motivo por el cual el Estado requerido no puede proceder al control de dicha competencia (art. 24), quedando además excluida cualquier revisión en cuanto al fondo (art. 26), incluido el control de la ley aplicada (art. 25). Estas consideraciones permiten señalar que el problema último que refleja la Decisión inglesa radica en la comprobación de la competencia judicial por los tribunales ingleses que conocieron del divorcio. A pesar de ello, la solución que adopta presenta una directa repercusión en relación con el reconocimiento, por los efectos que pudiera tener la anulación de las 91 sentencias inglesas firmes, de haberse presentado en Italia para solicitar su reconocimiento o la actualización de los datos del Registro civil como permite el art. 21 del Reglamento «Bruselas II bis». Se trata de una situación que no debiera haberse generado. El reconocimiento de aquellas sentencias presupone, de acuerdo con el Reglamento, la correcta comprobación de la competencia por los tribunales ingleses que, sin embargo, no fue suficiente en el momento en que se plantearon las demandas.

La eficacia de esta comprobación exige no sólo la mera constatación de la operatividad de alguno de los foros del Reglamento sino, además, ha de abarcar a la circunstancia sobre la que se articula el foro operativo en el caso concreto. Siendo ésta la que muestra la vinculación entre la situación y el Estado miembro cuyos tribunales pueden conocer del divorcio, la efectiva comprobación de la competencia requiere la constatación de la realidad de tal vinculación y, por tanto, de aquella circunstancia. En este sentido se puede considerar que la residencia habitual de uno de los cónyuges en Inglaterra, circunstancia de los foros operativos para la atribución de la competencia, no fue objeto de verificación por los tribunales ingleses en el momento de interposición de las demandas, que ni siquiera cuestionaron la posibilidad (credibilidad) de la dirección indicada. Esta comprobación se realiza con posterioridad, motivando que el fraude quedara descubierto iniciado el procedimiento o, lo que es más grave, cuando ya se había dictado sentencia. La anulación de estas sentencias es la respuesta de la Decisión. La seguridad jurídica se ve afectada pero, además, esta respuesta no puede conseguir atajar el auténtico problema de fondo y, por ello, no puede impedir que continúen existiendo casos similares, en tanto no se incremente la eficacia en la 
comprobación de la competencia. Aquí radica el problema y la prueba se constata en la propia Decisión inglesa cuando finaliza (\$§ 99-100) planteando los cambios normativos necesarios para impedir o, al menos, reducir estas situaciones de fraude, ya que todos ellos van dirigidos al aumento de aquella eficacia. En este sentido recoge la necesidad de modificar las normas inglesas (señaladas en § 10) en las que se han basado los «arquitectos» de este fraude para distribuir las 180 demandas a través de los tribunales de 137 condados. Una modificación que, como indica, se encuentra en marcha y pretende la centralización de la recepción de las demandas de divorcio, concentrándose en un número limitado de tribunales donde se conozcan los procedimientos especiales. A esta medida añade, por una parte, la necesidad de que la declaración jurada exigida en estos procedimientos se acompañara de una advertencia visible de las sanciones por falsedad y, por otra, el establecimiento de un sistema que permitiera al tribunal detectar si una misma dirección (para justificar la residencia habitual) hubiera sido empleada en varios casos.

4. Es posible que el mecanismo empleado para el fraude en los casos a los que la Decisión se refiere pueda ser paliado mediante tales medidas, a las que cabe añadir otra más obvia, como es la simple comprobación de la viabilidad de la dirección indicada como lugar de residencia habitual. Sin embargo, la maquinaria empleada para el fraude en estos casos, tan burda que roza lo increíble, no es la que, cabe pensar, se puede encontrar detrás de la mayor parte de los supuestos. La evidentemente falsa (por imposible) residencia habitual de uno de los cónyuges en Inglaterra, que pone de evidencia el fraude en los primeros, hubiera presentado otros contornos en el mismo caso de forum shopping fraudulento y concertado entre los cónyuges para internacionalizar una situación interna, cuando la dirección empleada para justificar la residencia habitual de uno de ellos correspondiera a una vivienda, por ejemplo alquilada con el único propósito y por el tiempo estrictamente necesario para elegir los tribunales ingleses. La residencia habitual también sería ficticia pero, al menos, creíble por posible. En estos casos, la constatación de la realidad de la residencia habitual como circunstancia del foro operativo y, por tanto, a los efectos de la comprobación de la competencia (ex art. 17 del Reglamento), presenta mayor dificultad.

Todo lo anterior refleja la importancia que hubiera presentado un concepto autónomo de «residencia habitual» en el propio Reglamento como se ha venido destacando por la doctrina [entre otros, BoNOMI, A., "Il Regolamento comunitario sulla competenza e sul riconoscimento in materia matrimoniale e di potestà dei genitori», RDI, 2001, núm. 2, pp. 298 y ss.; LAMONT, R., «Habitual residence and Brussels II bis: developing concepts for European private international Law», JPIL, 2007, pp. 261 y ss.; SALERNO, F., "I criteri di giurisdizione comunitari in materia matrimoniale», RDIPP, 2007, pp. 63 y ss.; RICCI, C., "Habitual Residence as a Ground of Jurisdiction in Matrimonial Disputes: From Brussels II bis to Rome III», en BariatTI, A., MalaTESTA, S. y Pocar, F. (dirs.), The External Dimension of EC Private International Law in Family and Succession Matters, Padua, Cedam, 2008, pp. 207 y ss.]. La ausencia de este concepto exige acudir a la interpretación derivada de la jurisprudencia del TJUE, aun viniendo referida a la «responsabilidad parental» (SSTJCE de 2 de abril de 2009, asunto C-523/07, A., y de 22 de diciembre de 2010, asunto C-497/10 PPU, Mercredi c. Chaffe), pudiendo señalarse que la determinación de la residencia habitual exige una combinación de los elementos subjetivos y objetivos puesto que, además de la presencia física del sujeto (con independencia del tiempo de duración que pudiera constatarse en el momento de apreciar la competencia), se han de verificar otros factores que permitan entender que no se trata de una mera presencia temporal, siempre sobre la base de datos fácticos, atendiendo a aspectos como el lugar donde el sujeto 
tiene el centro de sus intereses constatado mediante circunstancias de hecho como los vínculos sociales, la estabilidad de la residencia o la voluntad de permanencia, sin que en ningún momento se proceda al análisis o valoración de las razones de modificación de la residencia, ya que ha de respetarse la libertad de elegir el país donde el sujeto pretende establecerse. En cualquier caso y para evitar cualquier posible superposición entre los elementos fácticos, que se han de constatar, y la calificación de los motivos del traslado de la residencia, sería necesario que el TJUE aportara los parámetros uniformes para identificar la residencia habitual como criterio de los foros de competencia del art. 3 del Reglamento.

Esta delimitación tendría directa incidencia, de acuerdo con las razones expuestas, en la eficaz comprobación de la competencia por el tribunal donde se presenta la demanda y, por tanto, para combatir las situaciones de forum shopping fraudulento, unas situaciones que, no se olvide, siguen persistiendo a pesar de que su eliminación se encontraba entre los objetivos del Reglamento «Roma III» (Reglamento 1259/2010, de 20 de diciembre, por el que se establece una cooperación reforzada en el ámbito de la ley aplicable al divorcio y a la separación judicial) el cual únicamente consigue paliarlas, al mismo tiempo que puede suponer el incremento de las mismas si se atiende al contexto de la situación generada por el mecanismo de la «cooperación reforzada». La brecha abierta entre los dos grupos de sistemas para la determinación de la ley aplicable al divorcio [según que el Estado miembro al que pertenezcan los tribunales competentes sea (o no) un «Estado miembro participante»] constituye un importante atractivo para el desplazamiento ficticio de la situación cuando, ya sea el demandante o bien ambos cónyuges (forum shopping concertado), considerasen que la aplicación del sistema de uno u otro pudiera incidir de forma trascendente en sus intereses.

\author{
M. Ángeles SÁNCHEZ JimÉnEZ \\ Universidad de Murcia \\ http://dx.doi.org/10.17103/redi.67.1.2015.4b.07
}

